\title{
Advantages of Synthesizing trans-1,2-Cyclohexanediol
}

\section{in a Continuous Flow Microreactor over a Standard}

\section{Glass Apparatus}

\author{
Andreas Hartung,,$^{\dagger}$ Mark Keane, ${ }^{*}$ Arno Kraft ${ }^{*}{ }^{\dagger}$ \\ ${ }^{\dagger}$ Chemistry, School of Engineering \& Physical Sciences, Heriot-Watt University, Riccarton, \\ Edinburgh EH14 4AS, United Kingdom
}

${ }^{\ddagger}$ Chemical Engineering, School of Engineering \& Physical Sciences, Heriot-Watt University, Riccarton, Edinburgh EH14 4AS, United Kingdom

\section{Contents:}

General

Batch reaction: Reaction of Cyclohexene with Hydrogen Peroxide in Formic Acid. 2

Batch Reaction: Saponification of 3 and 4 to trans-1,2-Cyclohexanediol (5) 3

GC Analysis of the Product Mixture from Step 1 4

Photographs of Samples of the Product from Batch and Microreactor Process 6

${ }^{1} \mathrm{H}$ and ${ }^{13} \mathrm{C}$ NMR Analysis of Product Mixture from Step 1

${ }^{1} \mathrm{H}$ and ${ }^{13} \mathrm{C}$ NMR Spectra of trans-1,2-Cyclohexanediol (5) from Batch and Microreactor Process 14 


\section{Supporting Information}

General. All chemicals were purchased from chemical suppliers and used as received. Thin layer chromatography was carried out using Merck Kieselgel 60 F254 aluminum-backed plates; the plates were visualized after immersion into a potassium permanganate dip. ${ }^{1} \mathrm{H}$ and ${ }^{13} \mathrm{C}$ NMR spectra were recorded on a 200 or $400 \mathrm{MHz}$ spectrometer, with TMS serving as chemical shift reference. Melting points were determined by differential scanning calorimetry using a heating rate of $10{ }^{\circ} \mathrm{C} \min ^{-1}$. Allplastic (polypropylene) syringes were used, with no rubber piston seals as the latter tend to catalyze decomposition of $\mathrm{H}_{2} \mathrm{O}_{2}$. Syringe pumps were calibrated prior to use by dispensing and weighing a preset volume of water.

Batch reaction: Reaction of Cyclohexene with Hydrogen Peroxide in Formic Acid. ${ }^{1}$ Cyclohexene $(9.86 \mathrm{~g}, 0.12 \mathrm{~mol})$ was added within $5 \mathrm{~min}$ under stirring to an aqueous solution of hydrogen peroxide $(47 \%, 8.71 \mathrm{~g}, 0.12 \mathrm{~mol})$ and formic acid $(98 \%, 100 \mathrm{~mL})$. This procedure led to a rapid rise in temperature reaching $94{ }^{\circ} \mathrm{C}$ within a few minutes (see Figure S1). The mixture was then stirred at $70{ }^{\circ} \mathrm{C}$ for $2 \mathrm{~h}$. After removing the solvent in a vacuum, a yellow oil (15.0 g) was isolated consisting of a mixture of trans-1,2-cyclohexanediol monoformate (3), trans-1,2-cyclohexanediol diformate (4), trans1,2-cyclohexanediol (5), and traces of adipic acid. For GC analysis of a sample from the batch reaction, see Figure S2.

3: ${ }^{1} \mathrm{H}$ NMR (200 MHz, $\left.\mathrm{CDCl}_{3}\right) \delta 1.18-1.47$ (m, $\left.4 \mathrm{H}\right), 1.64-1.78$ (m, $\left.2 \mathrm{H}\right), 1.98-2.12(\mathrm{~m}, 2 \mathrm{H}), 3.43-$ $3.68(\mathrm{~m}, 1 \mathrm{H}), 3.55(\sim \mathrm{td}, J=9.7,4.6 \mathrm{~Hz}, 1 \mathrm{H}), 4.62(\mathrm{td}, J=9.1,5.0 \mathrm{~Hz}, 1 \mathrm{H}), 5.44$ (br. s, $1 \mathrm{H}, \mathrm{OH})$, $8.10(\mathrm{~s}, 1 \mathrm{H}, \mathrm{OCHO}) ;{ }^{13} \mathrm{C} \mathrm{NMR}\left(50 \mathrm{MHz}, \mathrm{CDCl}_{3}\right) \delta 23.6\left(\mathrm{CH}_{2}\right), 23.7\left(\mathrm{CH}_{2}\right), 29.9\left(\mathrm{CH}_{2}\right), 30.0\left(\mathrm{CH}_{2}\right)$, $72.2(\mathrm{CH}), 78.0(\mathrm{CH}), 161.3(\mathrm{CH}, \mathrm{OCHO}) ; R_{\mathrm{f}}$ (ethyl acetate) 0.50.

\footnotetext{
${ }^{1}$ Autorenkollektiv. Organikum: Organisch-chemisches Grundpraktikum, 19th ed.; Deutscher Verlag der Wissenschaften: Leipzig, 1993; 273.
} 
4: ${ }^{1} \mathrm{H}$ NMR (200 MHz, $\left.\mathrm{CDCl}_{3}\right) \delta 1.18-1.47$ (m, $\left.4 \mathrm{H}\right), 1.64-1.78$ (m, $\left.2 \mathrm{H}\right), 1.98-2.12(\mathrm{~m}, 2 \mathrm{H}), 4.85-$ $5.00(\mathrm{~m}, 2 \mathrm{H}), 8.02(\mathrm{~s}, 2 \mathrm{H}, \mathrm{OCHO}) ;{ }^{13} \mathrm{C} \mathrm{NMR}\left(50 \mathrm{MHz}, \mathrm{CDCl}_{3}\right) \delta 23.2\left(\mathrm{CH}_{2}\right), 32.8\left(\mathrm{CH}_{2}\right), 73.2(\mathrm{CH})$, $160.4(\mathrm{CH}, \mathrm{OCHO}) ; R_{\mathrm{f}}$ (ethyl acetate) 0.64 .

5: ${ }^{1} \mathrm{H}$ NMR (200 MHz, $\left.\mathrm{CDCl}_{3}\right): \delta 1.18-1.47$ (m, $\left.4 \mathrm{H}\right), 1.64-1.78$ (m, $\left.2 \mathrm{H}\right), 1.98-2.12(\mathrm{~m}, 2 \mathrm{H}), 3.26-$ 3.27 (m, 2 H, CHOH), 3.55 (br. s, $2 \mathrm{H}, \mathrm{OH}$ ). ${ }^{1} \mathrm{H}$ NMR (200 MHz, d 6 -DMSO): $\delta 1.00-1.18$ (m, $4 \mathrm{H}$ ), 1.49-1.59 (m, 2 H), 1.67-1.80 (m, 2 H), 3.03-3.14 (m, 2 H, CHOH), 4.55 (br. s, $2 \mathrm{H}, \mathrm{OH}) .{ }^{13} \mathrm{C}$ NMR $\left(50 \mathrm{MHz}, \mathrm{CDCl}_{3}\right): \delta 24.2\left(\mathrm{CH}_{2}\right), 32.8\left(\mathrm{CH}_{2}\right), 75.7(\mathrm{CH}, \mathrm{CHOH}) . R_{\mathrm{f}}$ (ethyl acetate) 0.32.

Adipic acid: ${ }^{1} \mathrm{H}$ NMR $\left(200 \mathrm{MHz}, \mathrm{CDCl}_{3}\right): \delta 2.31$ (one part of an $\mathrm{AA}$ 'XX' signal). ${ }^{13} \mathrm{C} \mathrm{NMR}(50 \mathrm{MHz}$, $\left.\mathrm{CDCl}_{3}\right): \delta 24.1\left(\mathrm{CH}_{2}\right), 33.3\left(\mathrm{CH}_{2}\right)$.

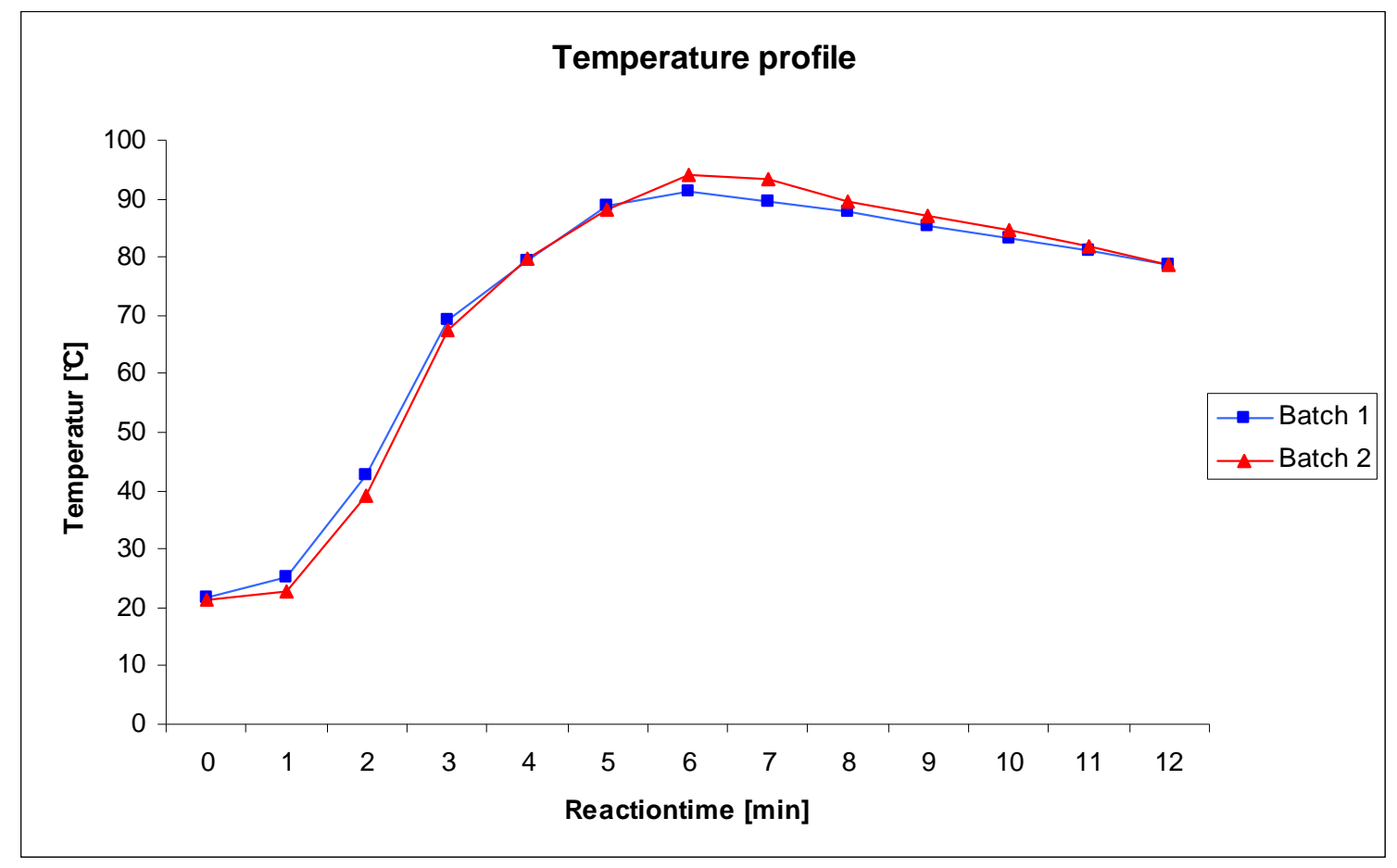

Figure S1. Temperature profile during the addition of cyclohexene to a solution of $\mathrm{H}_{2} \mathrm{O}_{2}$ in formic acid in two batch reactions.

Batch Reaction: Saponification of 3 and 4 to trans-1,2-Cyclohexanediol (5). ${ }^{1}$ A $20 \%$ solution of $\mathrm{NaOH}(50 \mathrm{~mL}, 0.25 \mathrm{~mol})$ was added to a mixture of $\mathbf{3}, \mathbf{4}$ and $\mathbf{5}(15.0 \mathrm{~g})$ and heated to $90{ }^{\circ} \mathrm{C}$ for $45 \mathrm{~min}$. The solution was neutralized with concentrated $\mathrm{HCl}$, and the solvent was then removed in a vacuum. 
The residue was extracted with chloroform $(6 \times 30 \mathrm{~mL})$ and the combined organic extracts were concentrated in a vacuum. Yield: $12.1 \mathrm{~g}(86 \%)$, brown solid. ${ }^{2} \mathrm{DSC}: 100.2{ }^{\circ} \mathrm{C}\left(95.9 \mathrm{~J} \mathrm{~g}^{-1}\right.$, lit. ${ }^{3}$ m.p. $\left.101.5-103{ }^{\circ} \mathrm{C}\right)$.

${ }^{1} \mathrm{H}$ NMR (200 MHz, $\left.\mathrm{CDCl}_{3}\right) \delta$ 1.13-1.28 (m, $\left.4 \mathrm{H}\right), 1.57-1.65(\mathrm{~m}, 2 \mathrm{H}), 1.83-1.93(\mathrm{~m}, 2 \mathrm{H}), 3.19-3.32$ (m, $2 \mathrm{H}), 4.64$ (br. s, $2 \mathrm{H}, \mathrm{OH}) ;{ }^{13} \mathrm{C}$ NMR $\left(50 \mathrm{MHz}, \mathrm{CDCl}_{3}\right): \delta .24 .2\left(\mathrm{CH}_{2}\right), 32.8\left(\mathrm{CH}_{2}\right), 75.4(\mathrm{CH}$, CHOH). Anal. Calcd for $\mathrm{C}_{6} \mathrm{H}_{12} \mathrm{O}_{2}$ : C, 62.04; H, 10.41. Found C, 59.37; H, 10.07.

GC Analysis of the Product Mixture from Step 1:

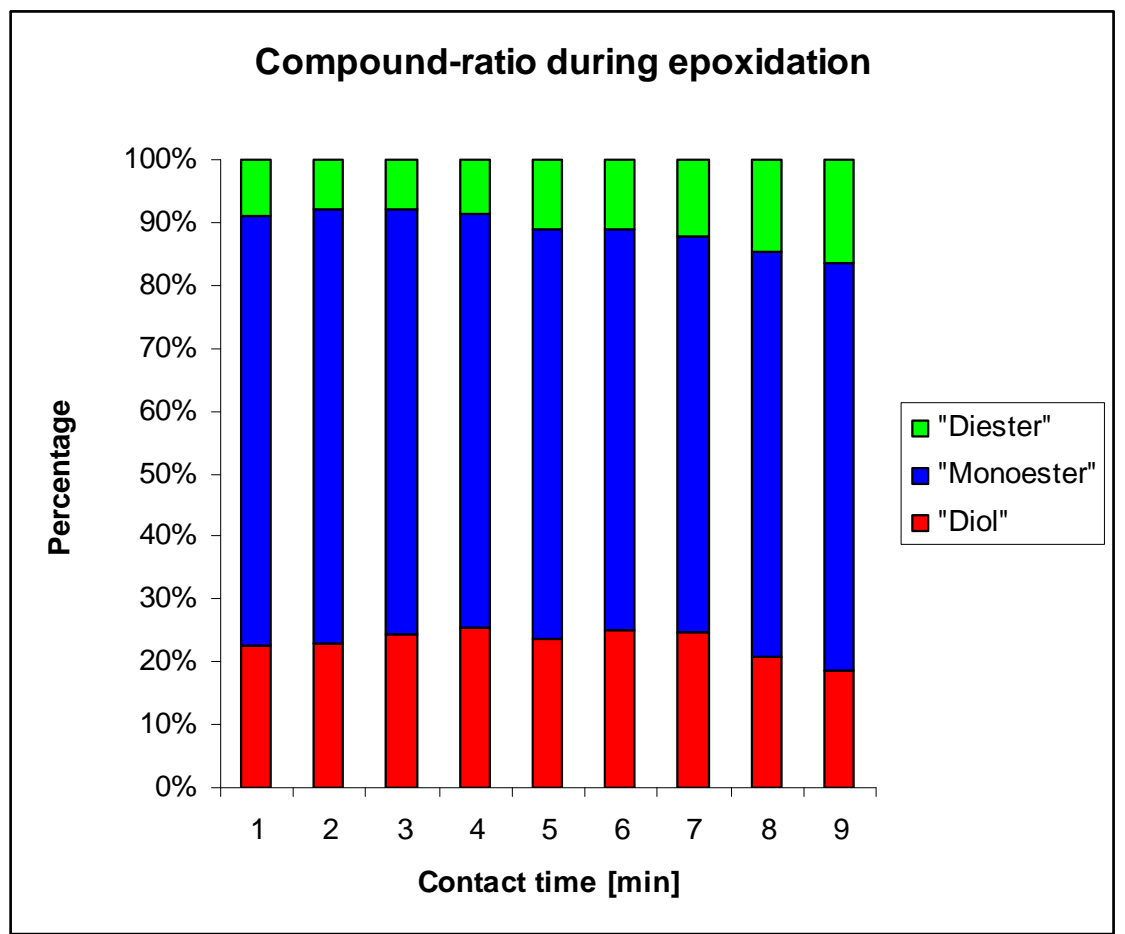

Figure S2. GC measurements indicated an almost constant ratio of monoester $\mathbf{3}$, diester $\mathbf{4}$ and diol $\mathbf{5}$ formed during the epoxidation of cyclohexene using a microreactor even at varying contact times. The results confirm the good controllability and the reproducibility that can be achieved in a microreactor.

\footnotetext{
${ }^{2}$ Literature ${ }^{1,3}$ yields were in the range of $65-73 \%$ after recrystallization or distillation.

${ }^{3}$ Roebuck, A.; Adkins, H. Org. Synth., Coll. Vol. III, 1955, 217-219.
} 


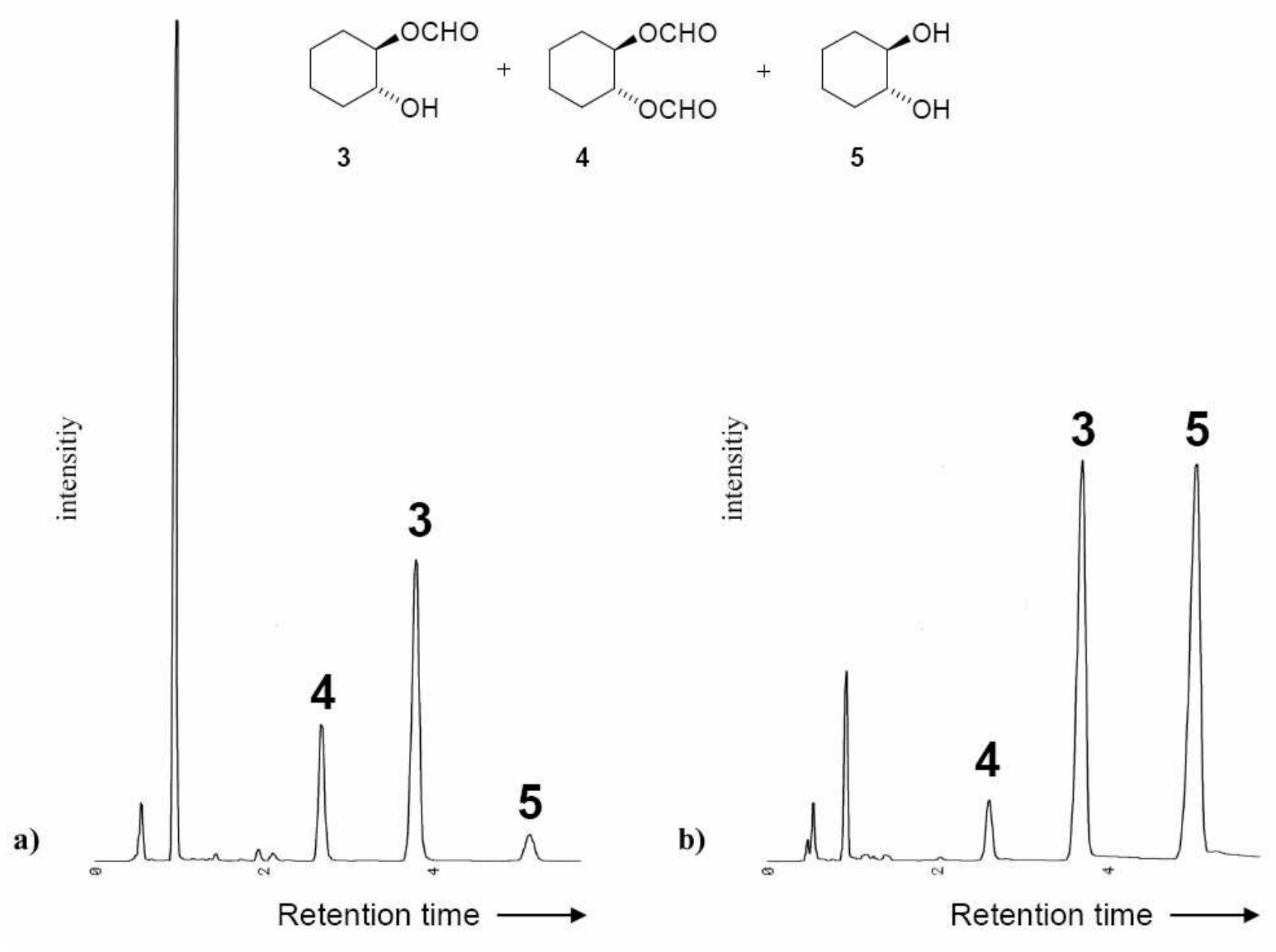

Figure S3. Characteristic GC spectra showing different product ratios in a microreactor (a) and in a batch reaction (b). GC conditions: Fused silica column $(5 \mu \mathrm{m}), 30$ meters long, $0.32 \mathrm{~mm}$ i.d., liquid phase RSL-160BP, oven temperature $150{ }^{\circ} \mathrm{C}$, injection temperature $270{ }^{\circ} \mathrm{C}$, no ramp rate. Retention times: $2.68 \min (\mathbf{4}), 3.79 \min (\mathbf{3}), 5.15 \min (\mathbf{5})$. 


\section{Photographs of Samples of the Product from Batch and Microreactor Process:}

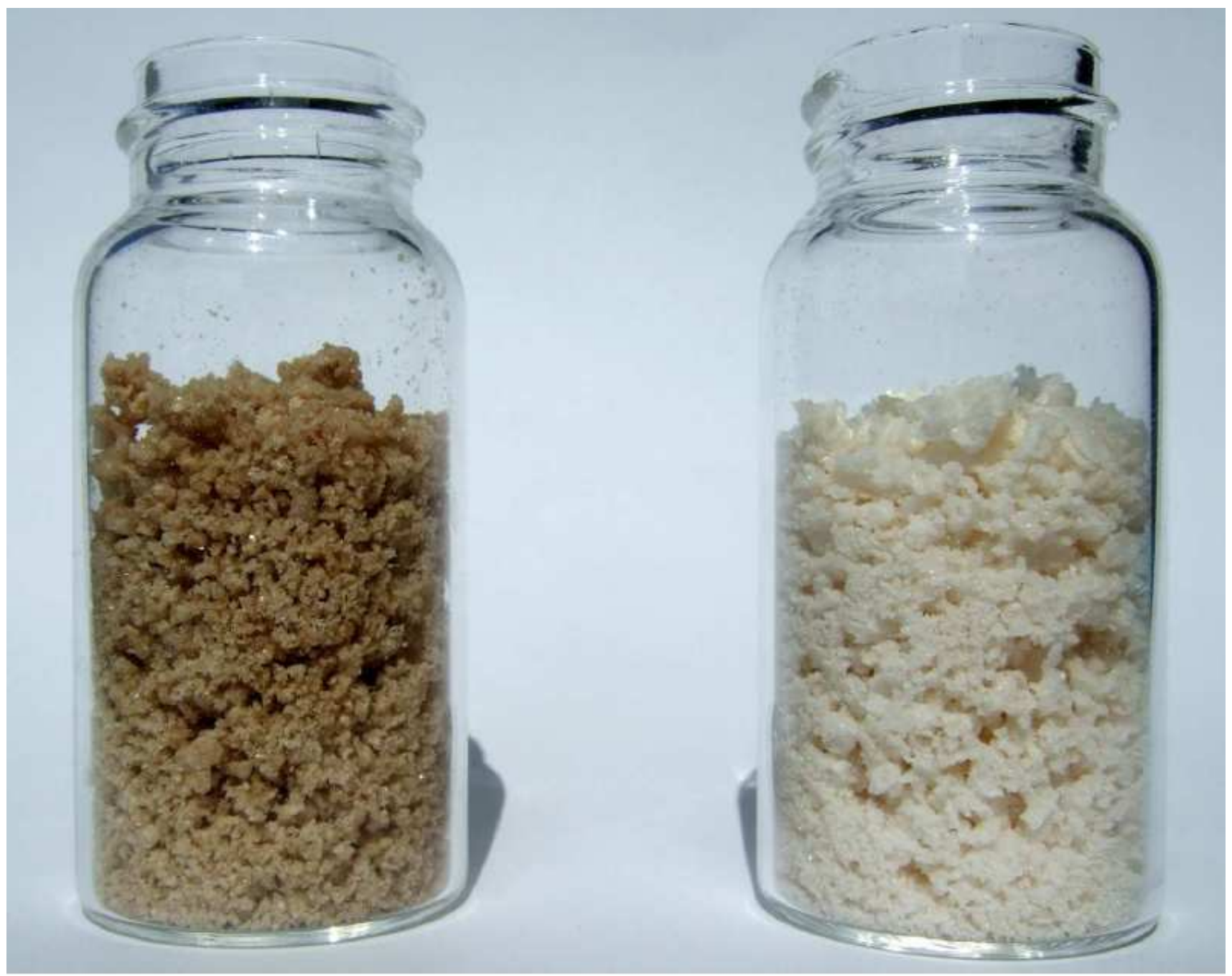

Figure S4. The batch reaction produced always a brown solid (left) of crude trans-1,2-cyclohexanediol (5), whereas the product which was isolated reproducibly from the continuous flow microreactor process (right) was colorless. 


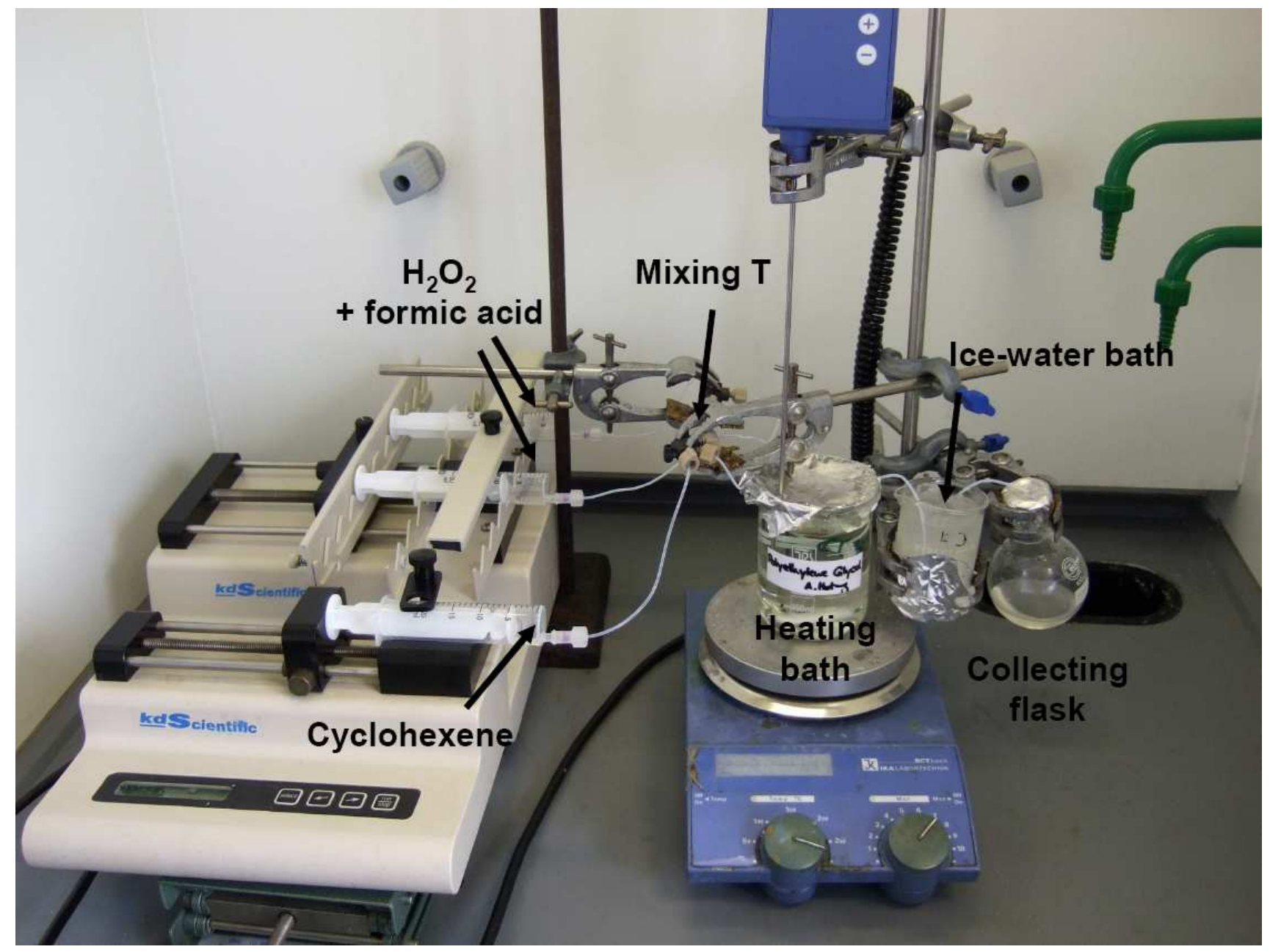

Figure S5. Experimental set-up for the reaction of cyclohexene (syringe, front left) and aqueous hydrogen peroxide (syringe, back left) in a microreactor. In this example, the $\mathrm{H}_{2} \mathrm{O}_{2}$ /formic acid reagent was initially split over two $20 \mathrm{~mL}$ plastic syringes and the contents were first combined into a single stream in a PEEK tee (thru-hole $1.25 \mathrm{~mm}$ ). The two reagent streams of $\mathrm{H}_{2} \mathrm{O}_{2} /$ formic acid and of cyclohexene were combined in a T mixer (thru-hole 0.020") before passing through a PTFE coil immersed in a poly(ethylene glycol) heating bath and then passing through an ice-water cooling bath. The final product was collected in a round-bottom flask (far right). 


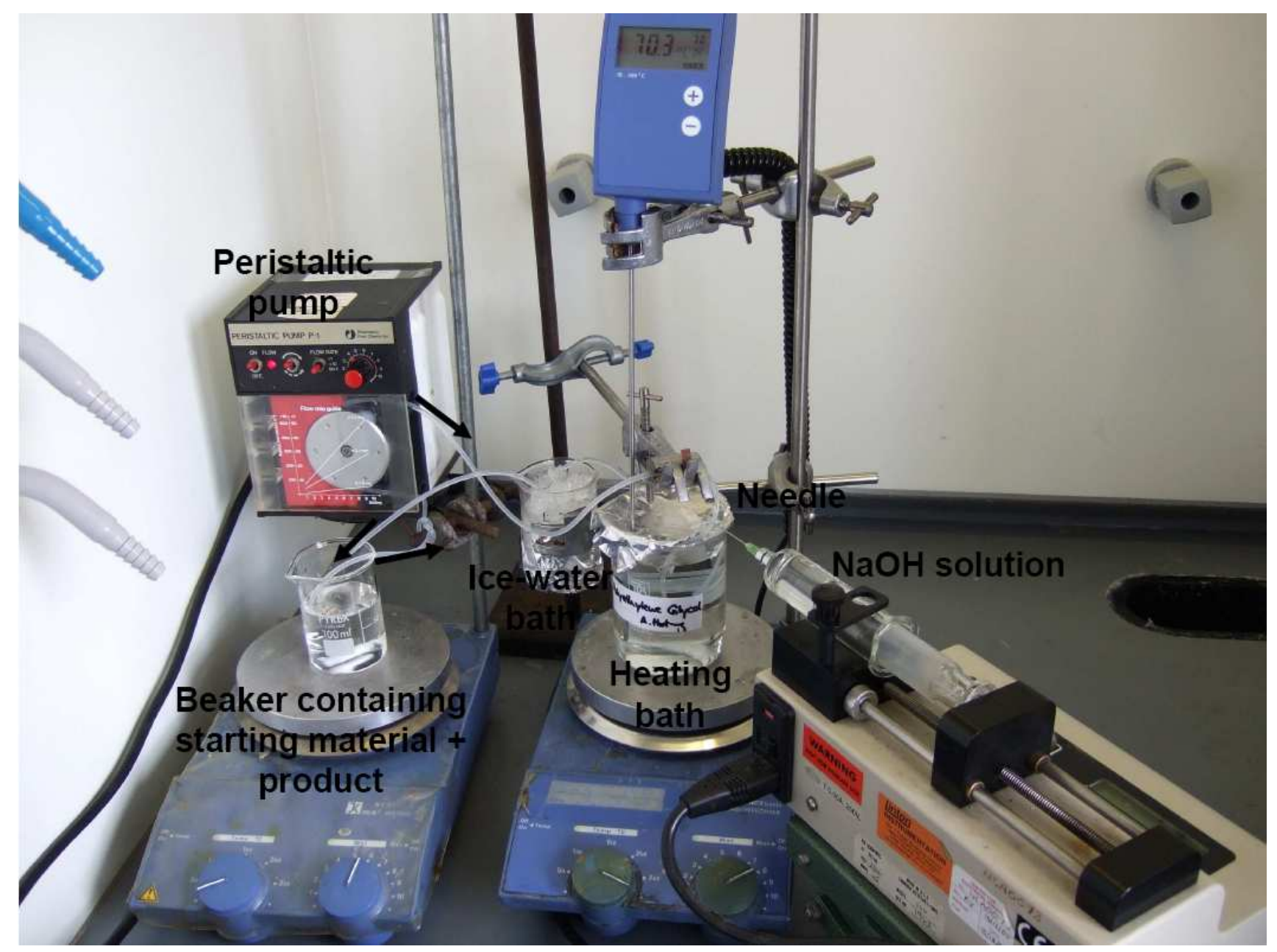

Figure S6. Experimental set-up for the saponification step 2 in a continuous flow recycle reactor. The solution of $\mathbf{3}, \mathbf{4}$ and $\mathbf{5}$ in aqueous methanol was placed into a beaker (left front) from which it was pumped through a silicone tubing with the help of a peristaltic pump (left back). Flow directions are indicated by arrows. An aqueous $\mathrm{NaOH}$ solution was injected into the reactant stream inside the tubing using a syringe pump, a syringe and a needle (right). The reactant $/ \mathrm{NaOH}$ mixture then passed through a heating bath (middle), an ice-water bath and was recycled back to the beaker again. 
${ }^{1} \mathrm{H}$ and ${ }^{13} \mathrm{C}$ NMR Analysis of Product Mixture from Step 1:

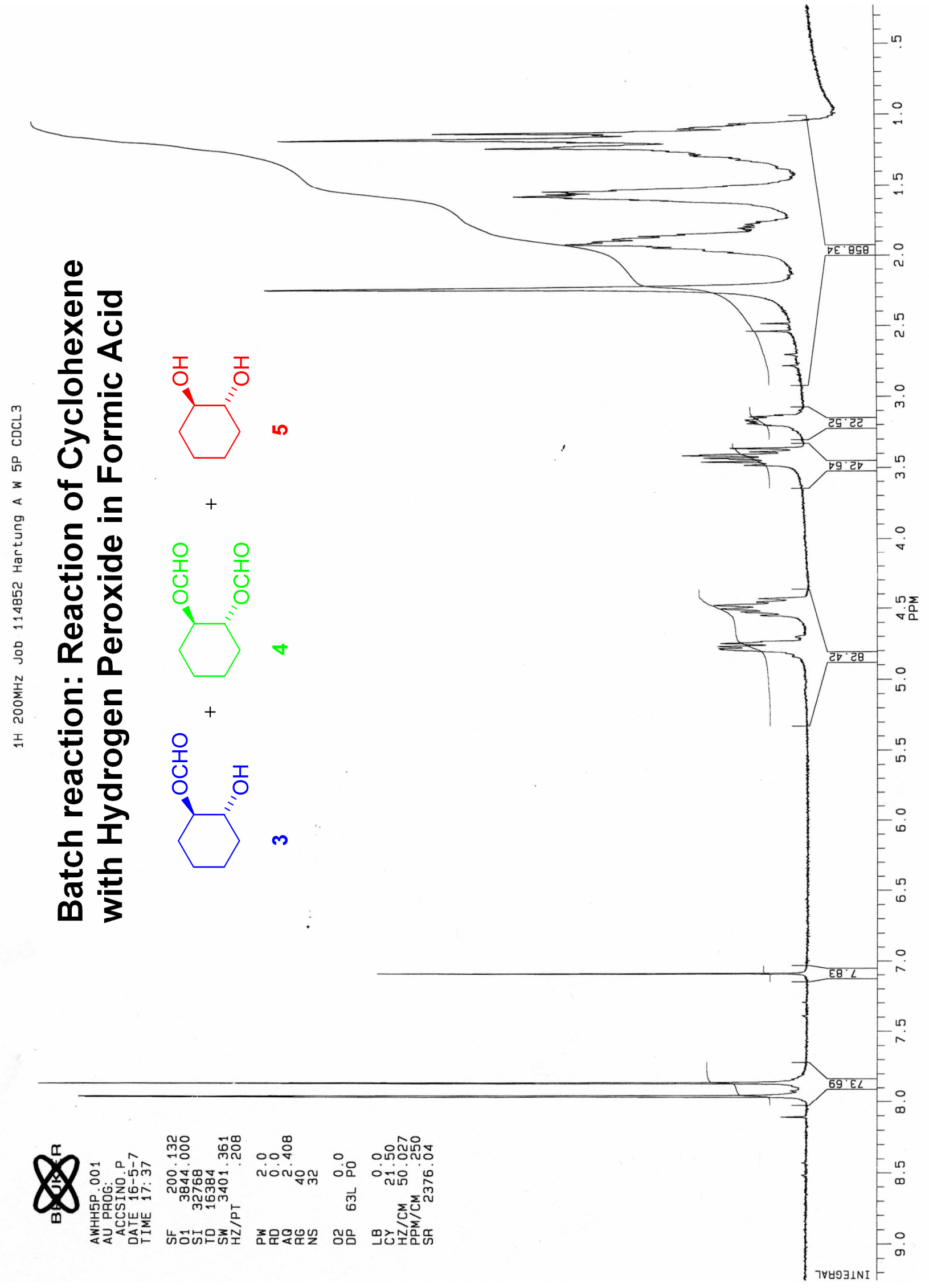



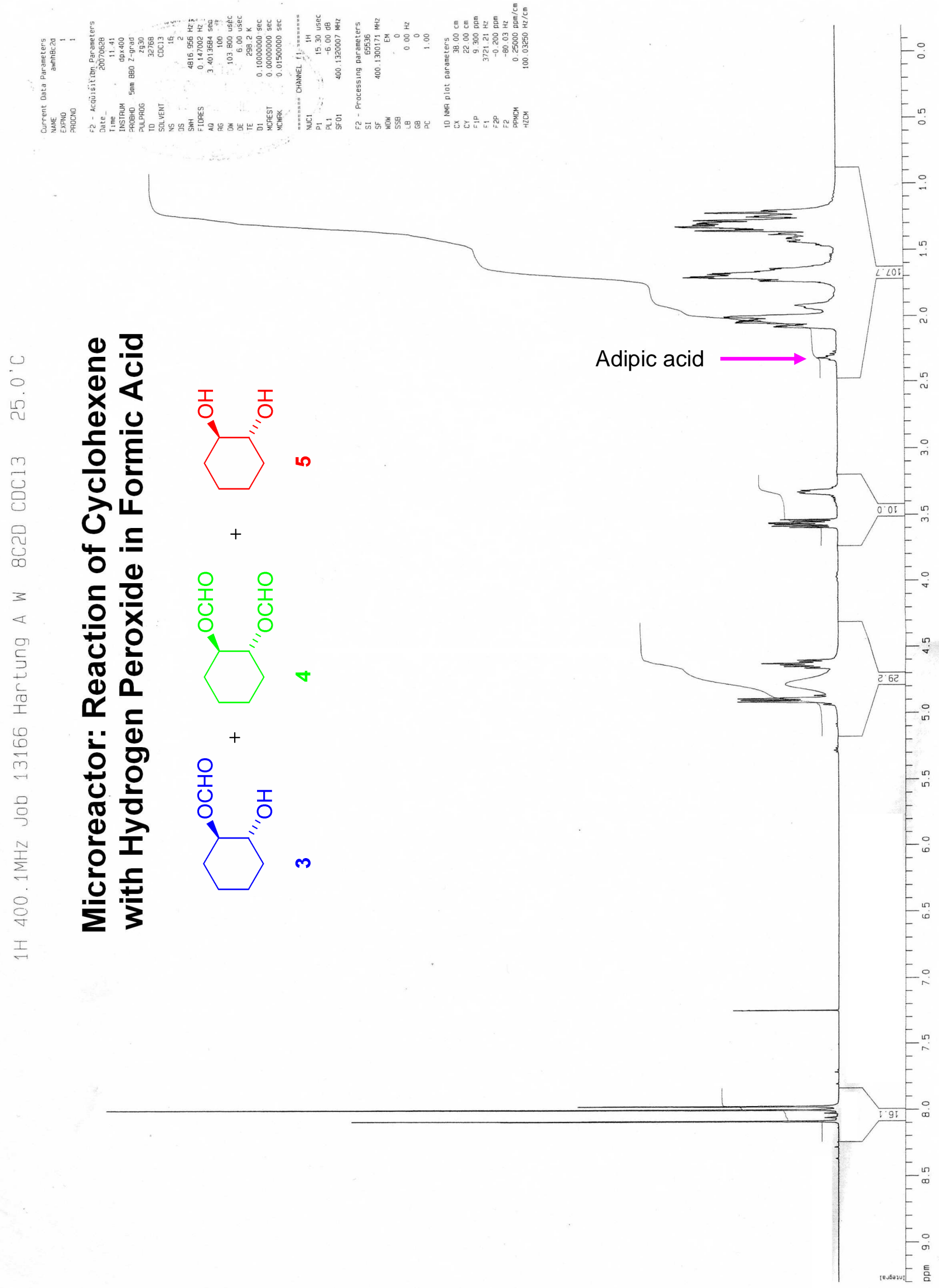


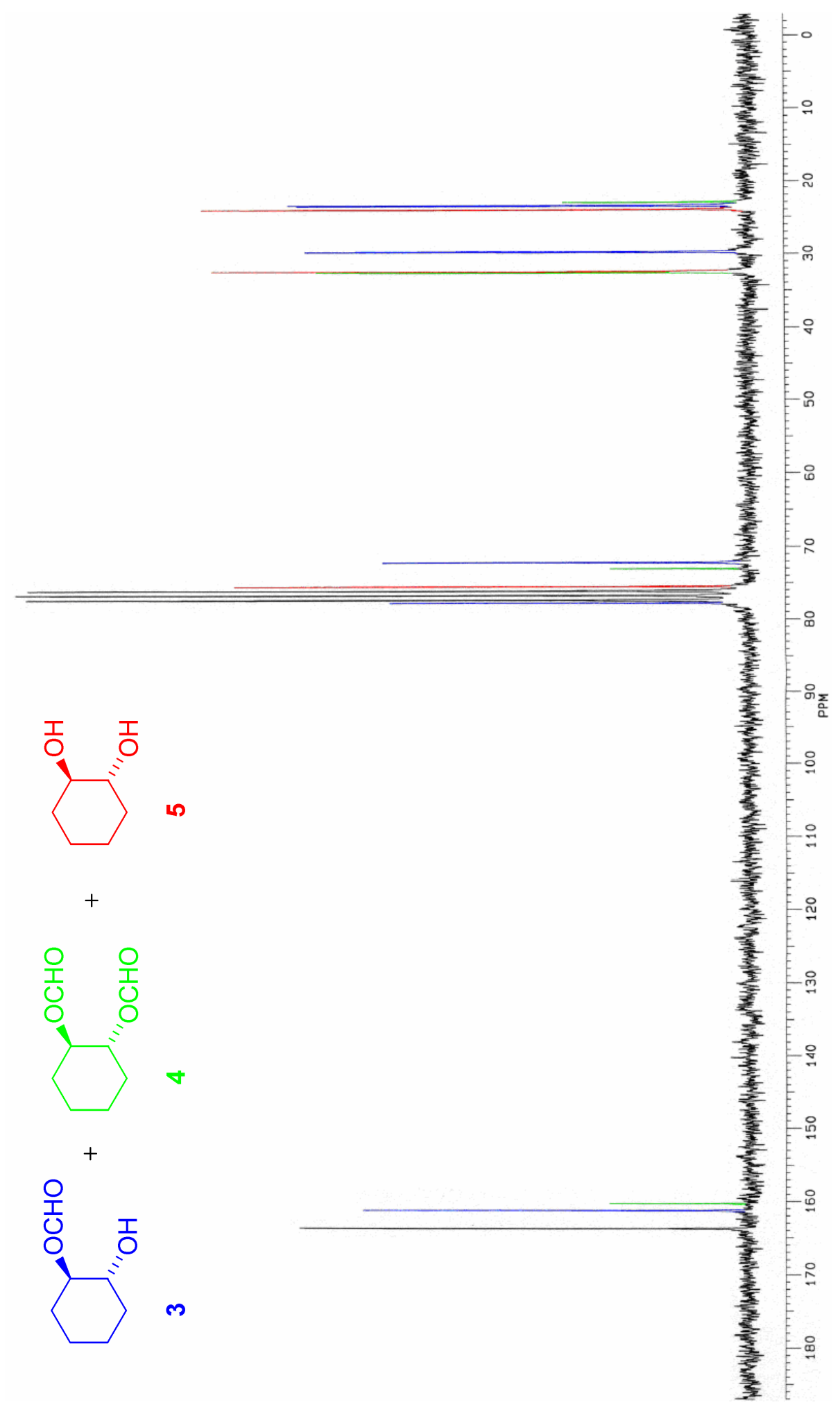

Figure S7. ${ }^{13} \mathrm{C}$ NMR of the compound mixture obtained after step 1 in the microreactor. The various signals of diol (5), monoester (4) and diester (3) are differentiated by separate colors. Residual solvent $\left(\mathrm{CDCl}_{3}\right.$, formic acid) signals are shown in black. 


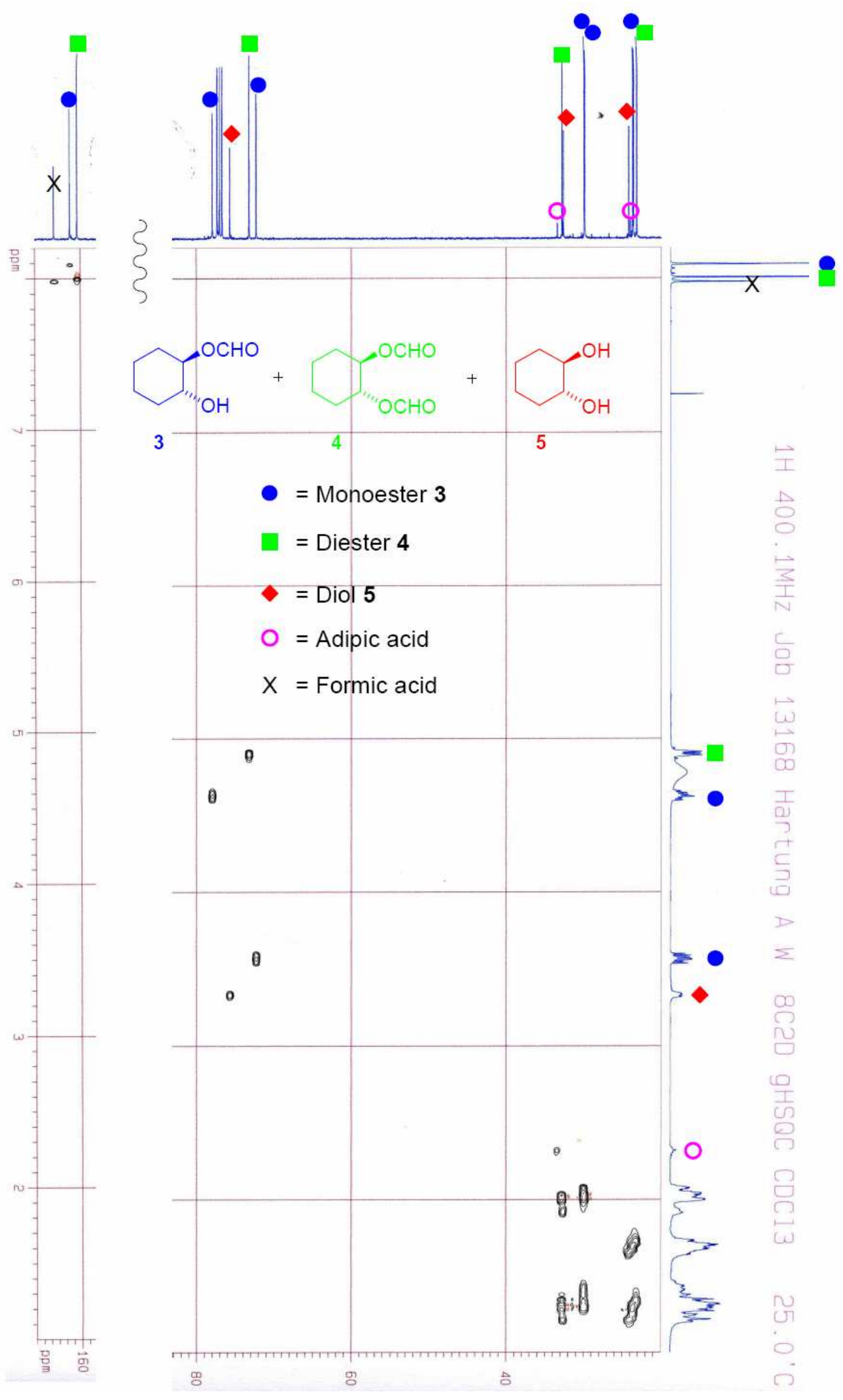


Figure S8. HSQC $2 \mathrm{D}{ }^{1} \mathrm{H} /{ }^{13} \mathrm{C}$ correlation NMR spectrum of the compound mixture obtained after step 1 in the batch reaction. NMR signals of diol (5), monoester (4), diester (3) and adipic acid are labelled using symbols of different colours. Residual solvent (formic acid) signals are shown marked by a black "X".

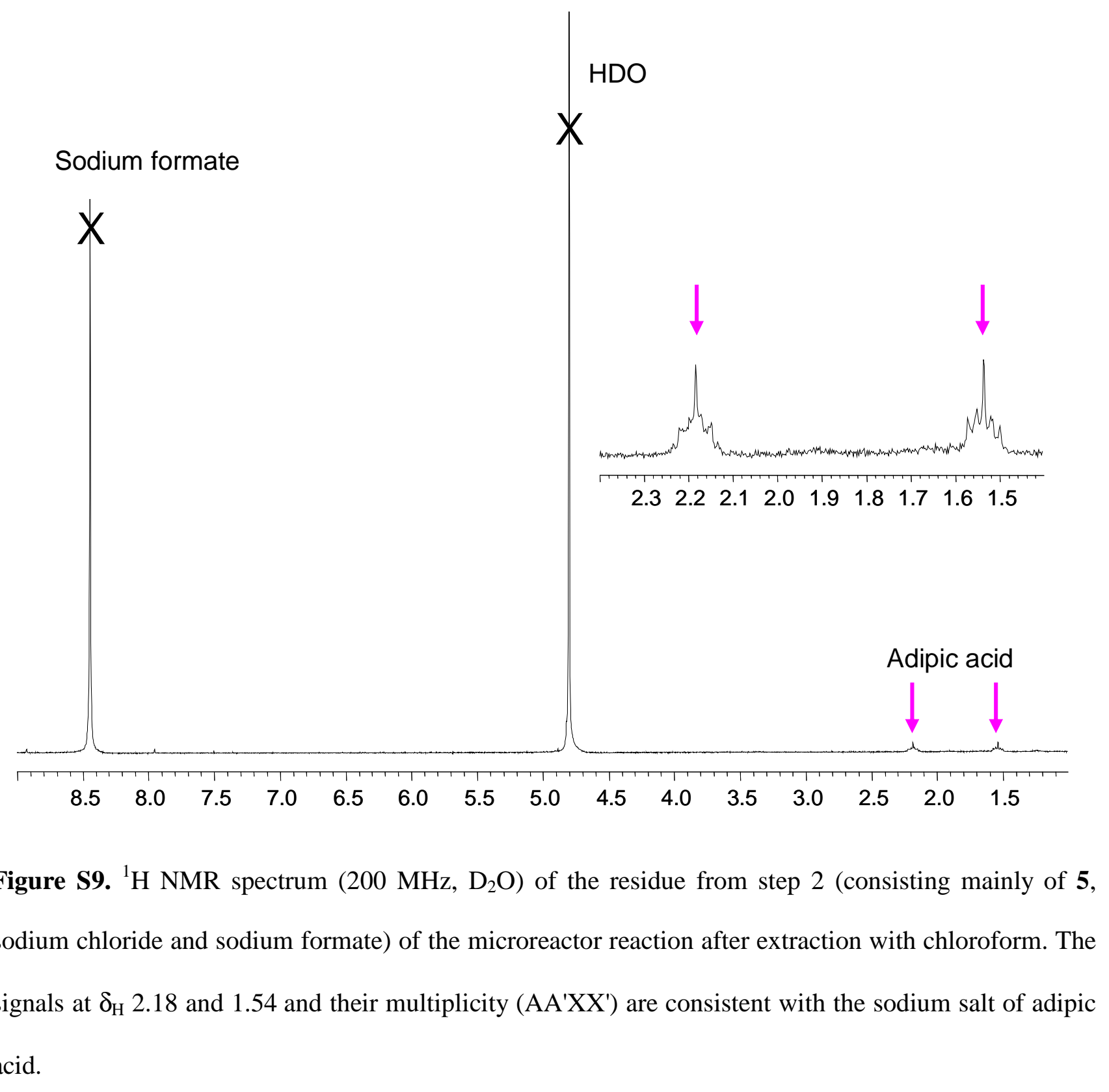


${ }^{1} \mathrm{H}$ and ${ }^{13} \mathrm{C}$ NMR Spectra of trans-1,2-Cyclohexanediol (5) from Batch and Microreactor Process:

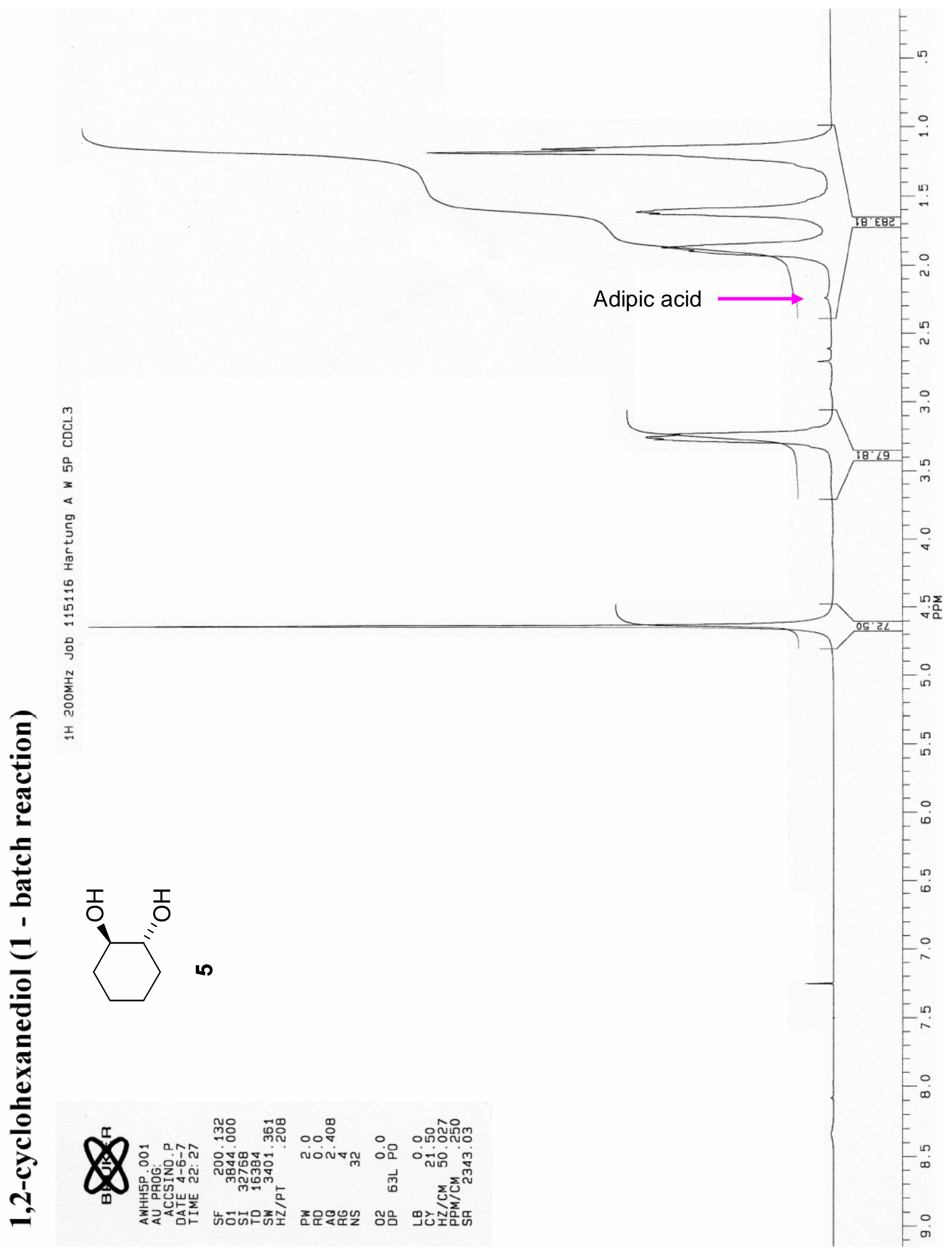




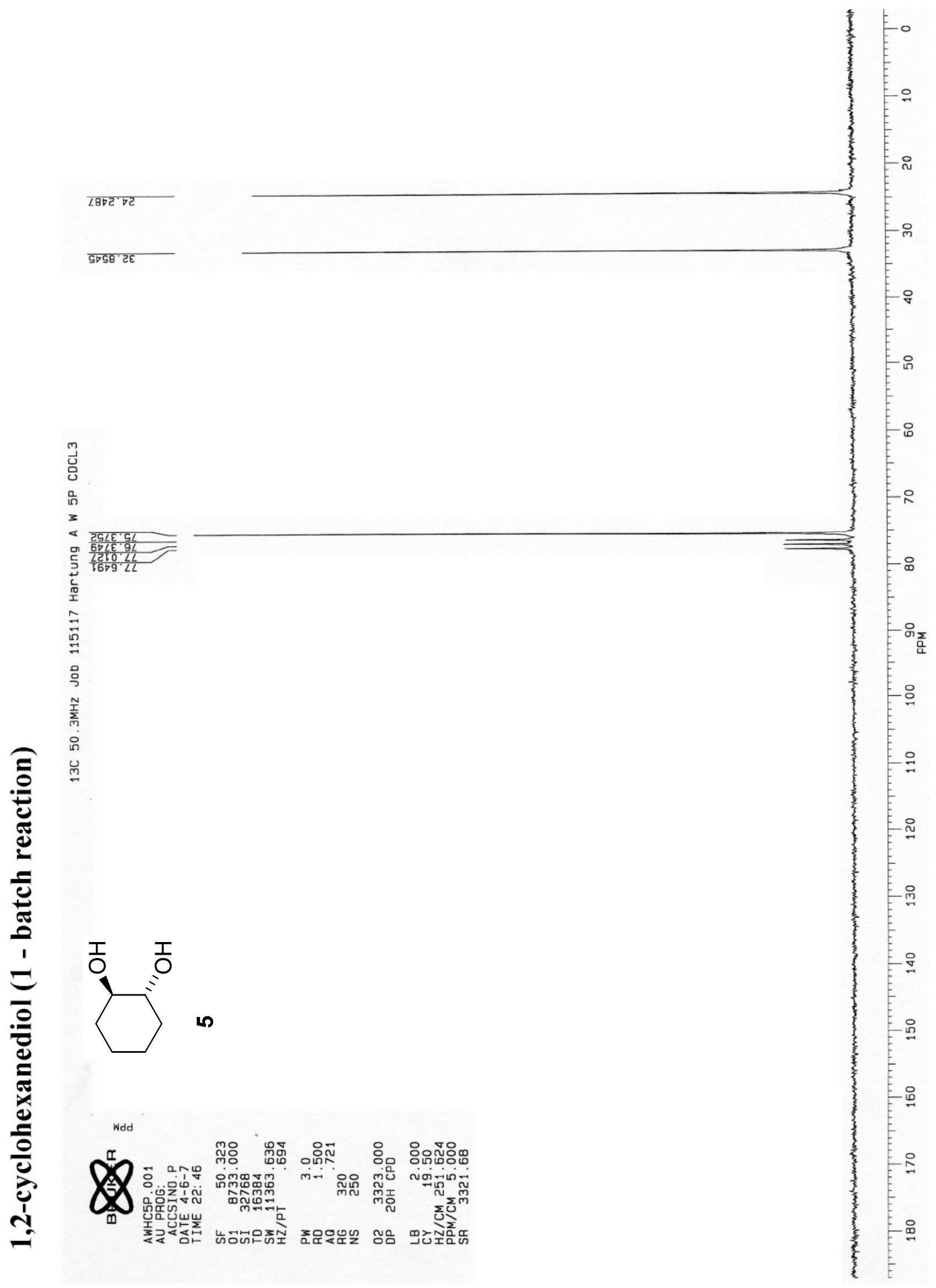




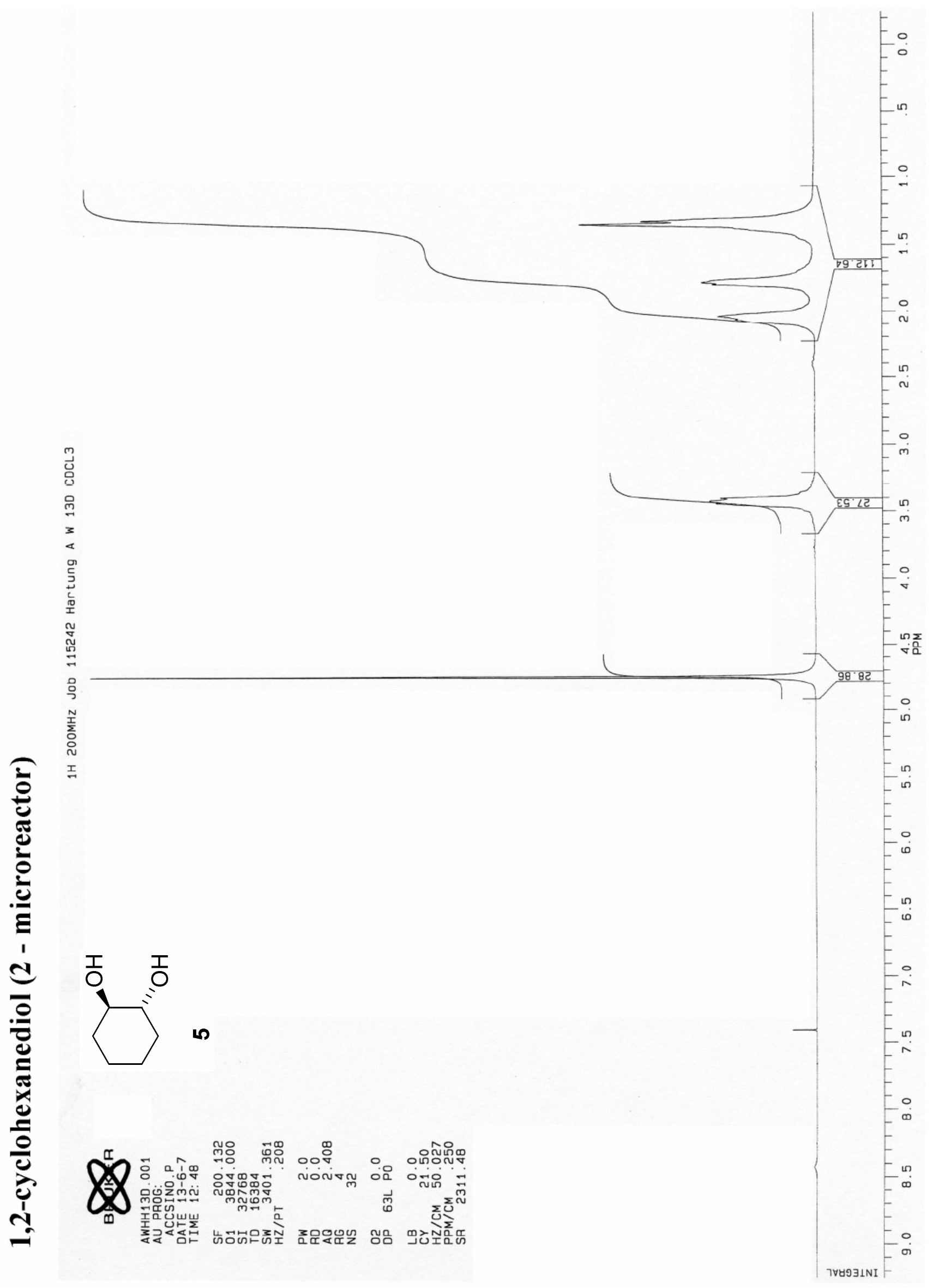




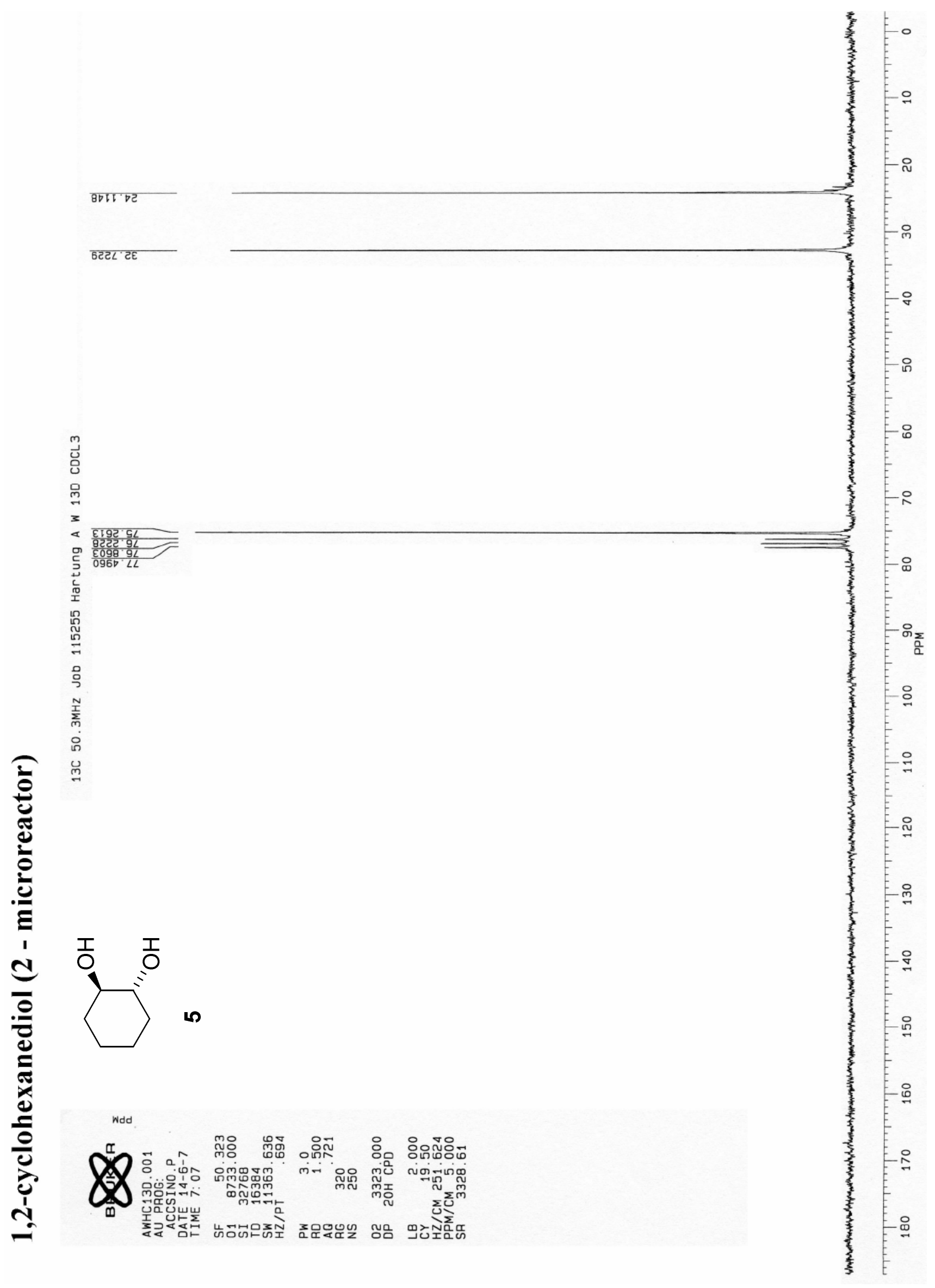

